\title{
Physico-chemical properties, antioxidant, and antimicrobial activity of five varieties of honey from Saudi Arabia
}

\author{
Mukhtar Ismail $^{a}$, Emad M. Abdallah ${ }^{b^{*}}$, Eman R. Elsharkawy ${ }^{\mathrm{c}, \mathrm{d}}$ \\ aDepartment of Chemistry, College of Sciences and Arts, Qassim University, Ar Rass, 51921 Saudi Arabia \\ ${ }^{b}$ Department of Science Laboratories, College of Science and Arts, Qassim University, Ar Rass, 51921 Saudi Arabia \\ 'Department of Ecophysiology, Desert Research Center, 15753 Cairo, Egypt \\ ${ }^{d}$ Department of Chemistry, Faculty of Science, Northern Borders University, 9280 Arar, Saudi Arabia
}

Received 5th May 2021 / Accepted 6th September 2021

\begin{abstract}
Wild honey is believed to have plentiful nutritional and health benefits. Numerous studies dealing with the characteristics and biological activities of honey have proved its biological activities. However, little is known about Saudi wild honey. In the current study, the physico-chemical properties, antioxidant and antimicrobial activity of five varieties of wild honey collected from different locations in Saudi Arabia were examined. Results showed that, the physico-chemical characteristics of all samples were in compliance with international standards. Qualitative and quantitative analysis of sugar (glucose, fructose and sucrose) was determined by high-performance liquid chromatography (HPLC). The analysis exhibited that fructose is the major sugar type in all examined wild honeys, which was found in highest concentration in flowers honey $(46 \mathrm{~g} / 100 \mathrm{~g})$, whereas, the lowest fructose concentration was found in Ziziphus honey (36 g/100 g). All monofloral honey showed significant antioxidant activity. Alfalfa honey recorded the highest antioxidant activity, followed by Ziziphus honey, respectively. However, Tamarisk honey recorded the lowest antioxidant activity among honey samples. Honey's antibacterial activity against five microorganisms displayed differing degrees of inhibition. The overall findings indicated that no antifungal activity was seen against Candida albicans. The antibacterial examination of honey samples revealed nonsignificant activity against all tested bacteria, except with Staphylococcus aureus ATCC BAA 1026, where the Acacia honey exhibited significant activity against this bacterium $(\mathrm{p}<0.05)$, with a mean of inhibition zone of $12.0+0.0 \mathrm{~mm}$ and a minimum inhibitory concentration of $12.5 \%$. The results of the other types of honey were statistically non-significant.
\end{abstract}

Keywords: antimicrobial, antibacterial, honey, chemical, physico-chemical, Saudi Arabia

\section{INTRODUCTION}

Honey is a natural product that has been commonly used for its medicinal effects since ancient times. Historic literature has shown that honey and bee products were utilized in medicine by ancient Egyptians, Greeks, and Romans, particularly for wound treatment and intestinal diseases (Eteraf-Oskouei \& Najafi, 2013). Honey is basically a saturated sugar solution, consisting of $82.4 \%$ carbohydrates (fructose, glucose, and other sugars), $17.1 \%$ water, and only $0.5 \%$ bioactive compounds like enzymes, vitamins, minerals, amino acids, phenolic compounds, flavonoids, carotenoids, ascorbic acid, $\alpha$ tocopherol, and tannins (Rossi \& Marrazzo, 2021). This $0.5 \%$ possibly carrying two healthpromoting effects: a curative effect, such as wound-healing, antioxidant, antimicrobial, antiparasitic and antidiabetic, and a protective effect on gastrointestinal, cardiovascular, nervous, and respiratory systems (Cianciosi et al., 2018) Honey

*Author for correspondence: Emad M. Abdallah, Department of Science Laboratories, College of Sciences and Arts, Qassim University, Ar Rass, 51921 Saudi Arabia. Email - emad100sdl@yahoo.com 
sugars are also extremely advantageous. As an example, fructo-oligosaccharides are indigestible compounds and may improve intestinal health since they are a decent source of prebiotics that help the probiotics in our intestines (Ramsay et al., 2019). Nevertheless, honey varies considerably in its properties depending on the plant species, its nectar, the climate, the environment, and the geographical distribution, and thus the chemical and therapeutic properties of honey also vary, and not all honey samples have the same medicinal properties (Abdallah, 2016). Depending on the plant origin, honey can be differentiated into two types: polyfloral (or multifloral) and monofloral (or unfloral) kinds of honey; the presence of pollen grains may provide information on plant composition, and it can also be useful in obtaining indications of geographical origin due to the spatial distribution of different plants (Utzeri et al., 2018). In the $21^{\text {st }}$ century, global comprehensive health schemes have been established based on synthetic compound libraries with apparent neglect of natural products (Lam, 2007). The human body has a diverse set of natural enzymatic and non-enzymatic antioxidant defenses that resist the formation of free radicals and other oxidants' harmful effects. A wide variety of illnesses, including cancer, neural disorders, cardiovascular diseases, atherosclerosis, Alzheimer's disease, Parkinson's disease, liver diseases, ulcerative colitis, and even ageing are caused by free radicals (Alam et al., 2013). In literature, honey as folk medicine is recommended as a natural antioxidant by many scientific reports (Al-Mamary et al., 2002; Bogdanov et al., 2008; Ahmed et al., 2018). The world continues to face the threats of ancient, emerging and renewable infectious diseases and that modern health system stands helpless in the face of recent outbreaks such as Ebola, dengue fever, Zika, influenza, Middle East respiratory syndrome, and severe acute respiratory syndrome, as well as the looming danger of increasing antimicrobial resistance (Bloom \& Cadarette, 2019). Therefore, it is expected that scientific research on natural products will witness a revival in search of good, holistic, and more effective treatment alternatives. The current study aimed to evaluate the physicochemical properties and antimicrobial activity of five brands of Saudi wild honey, one polyfloral and four monofloral honey.

\section{MATERIALS AND METHODS}

\section{Honey samples}

Five honey samples from different botanical origins were generously provided by Honey Jarbou stores, Unaizah city, Saudi Arabia. This company is committed to selling only wild kinds of honey which are raw and unpasteurized honey collected manually by the beekeepers from different localities in Saudi Arabia. Four monofloral and one polyfloral honey samples were investigated, namely Acacia honey (H1), Ziziphus honey (H2), Flowers' honey (H3), Alfalfa honey (H4), and Tamarisk honey (H5). Samples were acquired in June 2019 and were kept in well-tighten dark glass bottles under refrigeration at $4-5^{\circ} \mathrm{C}$ until analysis.

\section{Microorganisms}

Four referenced bacterial strains and one yeast strain were used in this investigation. Bacterial strains are two Gram-positives (Staphylococcus aureus ATCC BAA 1026 and Bacillus cereus ATCC 10876), two Gram-negatives (Pseudomonas aeruginosa ATCC 10145 and Escherichia coli ATCC 1637), and the yeast strain was Candida albicans ATCC 10231. All microbial isolates were obtained from the stock culture of the Department of Laboratory Sciences, College of Sciences and Arts at Al-Rass, Qassim University, Saudi Arabia.

\section{Physico-chemical analyses}

Five honey samples solution $50 \%$ (w/v) were prepared using distilled water at room $20^{\circ} \mathrm{C}$. The resulting solution was used to determining the physico-chemical parameters such as $\mathrm{pH}$, electrical conductivity, density, ash content, and element analysis.

\section{$p H$ values}

The $\mathrm{pH}$ of the samples was measured by using a $\mathrm{pH}$ meter (Martini, Mi 180 Bench Meter) according to the harmonized methods (Abdeellah et al., 2020).

\section{Electrical conductivity}

The electrical conductivity (EC) of samples was measured at $20^{\circ} \mathrm{C}$ with the aid of a conductivity meter (Thermo Scientific, Orion Star A212) (Svečnjak et al., 2019). 


\section{Density}

The pycnometry method (Lullah-Deh et al., 2018) was used to determine the density of the honey samples using the expression below:

$$
\mathrm{D}=\mathrm{M}_{2}-\mathrm{M}_{1} / \mathrm{V}
$$

$\mathrm{M}_{1}=$ mass of the pycnometer when empty

$\mathrm{M}_{2}=$ mass of the pycnometer filled with honey sample

$\mathrm{V}=$ volume of the pycnometer

\section{Ash content}

Ash content was determined according to the dryash method (Sajid et al., 2020; Ahmed et al., 2007). Ten grams of each sample was placed in the burning crucibles. The crucibles were placed in Electric Muffle Furnace (JISICO J-FM38, South Korea) at $500^{\circ} \mathrm{C}$ for two hours. The proportion of ash WA in $\mathrm{g} / 100 \mathrm{~g}$ honey is calculated using the following formula:

$$
\mathrm{WA}=\mathrm{M}_{1}-\mathrm{M}_{2} / \mathrm{M}_{0}
$$

$\mathrm{M}_{0}=$ weight of honey taken,

$\mathrm{M}_{1}=$ weight of crucible + ash

$\mathrm{M}_{2}=$ weight of crucible

\section{Element analysis}

Elemental analysis was carried out using Thermo scientific EDXRF Analyzer QTX-1024. $1 \mathrm{~g}$ of five raw honey samples were placed in special cups (Lazaridou et al., 2004; Aljohar et al., 2018).

\section{Quantitative analysis of sugar by $L C$}

The sugar of honey samples was analysed by injecting the sample on an injector with a $20 \mathrm{~L}$ loop on the system. The column was Water Radial-pak silica $(7: 100 \mathrm{~mm})$, reagents (glucose, fructose and sucrose) standards are from SigmaAldrich. Methanol, acetonitrile and water all HPLC grad sensitive balances were used. Acetonitrile and water (75:25) were mixed, sonicated and used as mobile phase. HPLC conditions flow rate: $1.5 \mathrm{~mL} / \mathrm{min}$; mobile phase: acetonitrile: water $(75: 25, \mathrm{v} / \mathrm{v})$; column and detector temperature: $30^{\circ} \mathrm{C}$, and sample volume: $20 \mu \mathrm{L}$ were used for HPLC separation. Peaks were identified on the basis of their retention times.

\section{Preparation of sample}

Selected honey samples were weighed $(2.5 \mathrm{~g})$ in two a $250 \mathrm{ml}$ flask dissolved in $20 \mathrm{ml}$ of HPLC grade water, $12.5 \mathrm{ml}$ of methanol was added after that honey solution was filtered through a nylon membrane filter syringe (Bogdanov, 2009).

\section{DPPH radical scavenging capacity}

The DPPH radical scavenging activity of honey samples was assayed as a method described (Elsharkawy \& Shiboob 2017; Brand-Williams 1995). Ascorbic acid was used as the positive control. the radical scavenging activity was expressed as \% DPPH inhibition calculated from the graph of inhibition percentage plotted.

\section{Antimicrobial disc-diffusion susceptibility method}

Kirby-Bauer Disk Diffusion Susceptibility Test Protocol has been used as described by (Bakht et al., 2011) to evaluate the potential antimicrobial activity of honey samples. Briefly, under aseptic conditions, plates containing nutrient agar were prepared and left to solidify. Five sets of filter paper discs (6 $\mathrm{mm}$ in diameter) were cut from Whatman No. 1 filter paper and each set was saturated separately with the desired honey solution at $50 \% \mathrm{v} / \mathrm{v}$ using sterile distilled water. The solidified agar plates were inoculated with 18 to $24 \mathrm{~h}$ cultures of microbial inoculums (about 1 to $2 \times 10^{7} \mathrm{CFU} \mathrm{m}{ }^{-1}$ ), using sterile cotton swabs. Then, the saturated discs were put over the nutrient-agar plats. Discs saturated with chloramphenicol $(1.25 \mathrm{mg} / \mathrm{ml})$ for bacteria and Clotrimazole $(2.5 \mathrm{mg} / \mathrm{ml})$ for yeast were also loaded and served as positive controls. In separate inoculated plates, discs saturated with the solvent (80\% methanol) were evaluated and showed no inhibitory effects. Plates were incubated at $35^{\circ} \mathrm{C}$ for 18 to $24 \mathrm{~h}$ for bacteria, or for $48 \mathrm{~h}$ for yeast and then inspected for inhibition zones around the discs, which was recorded in millimeter using a ruler. The test was repeated twice and the mean zone of inhibition \pm standard error of means was calculated. Zones have been interpreted as weak if it was less than $10 \mathrm{~mm}$, moderate of the zone of inhibition was between 10 and $13 \mathrm{~mm}$, and high if the zone of inhibition was greater than $13 \mathrm{~mm}$ (Abdallah, 2020). 


\section{Minimum inhibitory concentration method}

Microorganisms that showed susceptibility to honey samples from the $10.0 \mathrm{~mm}$ inhibition zone and above were subjected to minimum inhibitory concentration (MIC) using the agar well diffusion method (Gonelimali et al., 2018). Under aseptic conditions, two-fold serial dilutions were prepared to get decreasing concentrations starting from 25. 12.5, 6.3, 3.1, and $1.6 \% \mathrm{v} / \mathrm{v}$ using distilled water. $1 \mathrm{ml}$ of each prepared inoculum of tested bacteria was transferred to a nutrient-agar Petri-dish and spread over the plate using a sterile cotton swab. Then, 5 wells (size $6 \mathrm{~mm}$ ) were made on each plate by a sterile cork-borer and each honey dilution was loaded into the wells in order. Inoculated plates were then incubated at $35^{\circ} \mathrm{C}$ for $18 \mathrm{~h}$ (for bacteria) for up to $48 \mathrm{~h}$ (for yeast). The MIC was described as the lowest concentration that inhibited the growth of the microorganisms.

\section{Statistical analysis}

The findings of this study are stated as mean \pm SEM (Standard Error of Means). One-Way ANOVA (analysis of variance) test was used to determine the important variations between the examined microorganisms, for statistical analysis, SPSS program 14.0 (SPSS Inc., Chicago, USA) was used.

\section{RESULTS AND DISCUSSION}

\section{Physico-chemical properties}

The results of the physicochemical parameters analyzed are shown in Table 1 and the Element analysis is shown in Table 2. As for the colour, it was noted that honey colours vary between dark amber, light amber, and white. The difference in colour is due to the difference in the percentages of dissolved substances in the origin of the plant, such as the pigment compounds that are transported through nectar and are rich in chlorophyll and carotene. The effect is also due to the proportion of minerals and mineral salts that vary according to the type of plant. In addition, the temperature and storage conditions affect the honey colour (Bouhlali, et al., 2019). The pH values of honey samples correspond to international specifications; the values ranged between 3.44 to 4.83 honey is considered an acidic medium and the difference in acidity values between honey samples is due to several reasons, including the period of maturity, the type of flowering, as well as the chemical composition of honey, the concentration of minerals, the phenols in it, the percentage of acids in addition to mineral concentrations (Laaroussi et al., 2020). Generally, the density values obtained for honey samples comply with international specifications (LullahDeh et al., 2018). The values ranged between 1.1 to 1.16; the lowest value for honey sample 1 and the highest value for sample 5 , and the variation of these values is due to the density being affected by storage or neglecting to close storage vessels (Perez-Arquillué et al.,1994). According to the results in Table 1 , the conductivity of the samples values ranged between 0.4 to $8.63 \mathrm{mS} / \mathrm{cm}$, and the highest value of the conductivity is for sample 1 , and the reason is that bees graze on the flowers of sample 1 that are located in salty areas. Compared to the areas where other samples are located, in addition, the mineral concentration for sample 1 is much higher than the other samples, and this directly affects its conductivity. Ash content is a quality measure for plants and the geographical origin of honey. In this study, honey sample 2 has a higher ash content $(0.19 \%)$ compared with the other samples. Ash content of honey samples was within the acceptable range (0.6-1.2\%) mentioned in previous research (Alqarni, et al., 2014). The results of element analysis of honey samples by XRF instrument showed that potassium was the major mineral ranged between $48.9 \%$ and $10.1 \%$, followed by aluminum (between $42.9 \%$ and 10.47\%), calcium (between 3.4\% and 1.6\%), and ion in the lowest amount (between $0.05 \%$ and $0.08 \%$ ). The mineral contents in this study were within the range reported in honey (Solayman et al., 2016; Adugna et al., 2020). The study also showed that some of the honey samples contain non-metal such as chlorine, bromine, sulfur, and phosphor. In addition to minerals, honey sample 2 contain heavy metals. The mineral content in honey is an important pointer of potential environmental pollution, especially for heavy metals, and it is a possible indicator of honey's geographical origin (Ribeiro et al., 2014; Otaka et al., 2014). 
Table 1. Physico-chemical properties of the five honey samples.

\begin{tabular}{cccccc}
\hline $\begin{array}{c}\text { Honey } \\
\text { Samples }\end{array}$ & Colour & $\mathbf{p H}$ & $\begin{array}{c}\text { Density } \\
\mathbf{( g / \mathbf { c m } ^ { 3 } )}\end{array}$ & $\begin{array}{c}\text { Electrical } \\
\text { conductivity } \\
(\mathbf{m S} / \mathbf{c m})\end{array}$ & Ash (\%) \\
\hline Sample 1 & Dark amber & 4.8 & 1.10 & 8.63 & 1.15 \\
Sample 2 & Light Amber & 4.83 & 1.11 & 1.78 & 0.19 \\
Sample 3 & Light Amber & 3.85 & 1.12 & 1.07 & 0.1 \\
Sample 4 & Extra White & 3.44 & 1.11 & 0.4 & 0.09 \\
Sample 5 & Light Amber & 4.26 & 1.16 & 3.2 & 0.1 \\
\hline
\end{tabular}

Table 2. Results of element analysis of the five honey samples.

\begin{tabular}{ccccccccccccc}
\hline Honey & \multicolumn{10}{c}{ The percentage of elements analysis (m/m) \% } \\
\cline { 2 - 14 } samples & $\mathbf{K}$ & $\mathbf{A l}$ & $\mathbf{C a}$ & $\mathbf{F e}$ & $\mathbf{C l}$ & $\mathbf{B r}$ & $\mathbf{S}$ & $\mathbf{P}$ & $\mathbf{Z n}$ & $\mathbf{~ N i}$ & $\mathbf{M n}$ & $\mathbf{R b}$ \\
\hline Sample 1 & 48.9 & 10.47 & 3.4 & 0.05 & 4.47 & 0.07 & 2.14 & 2.8 & 0.07 & 0.02 & - & 0.02 \\
Sample 2 & 32 & 28.2 & 2.1 & 0.08 & 4.9 & - & - & - & 0.09 & - & 0.06 & - \\
Sample 3 & 10.1 & 42.9 & 1.6 & - & 3.1 & - & 0.6 & - & - & - & - & - \\
Sample 4 & 9.0 & 38.67 & 5.57 & - & 6.81 & - & 0.53 & 0.09 & 0.04 & & & - \\
Sample 5 & 21.8 & 30.4 & 2.8 & - & 6.1 & 0.03 & 1.1 & - & - & - & - & - \\
\hline
\end{tabular}

\section{Quantitative analysis of sugar in honey samples by HPLC}

Sugar is a major compound of Carbohydrates in the honey bee that gives honey its quality and it is related to maturity and its origin. The results of the analysis of five samples of different content (glucose, fructose, and sucrose) are shown in (Table 3). The maximum concentration of glucose was found in Tamarisk honey $(38.5 \mathrm{~g} / 100 \mathrm{~g})$ and minimum concentration $(24 \mathrm{~g} / 100 \mathrm{~g})$ was found in sample H1 (Acacia honey), while fructose showed high concentration $(46 \mathrm{~g} / 100 \mathrm{~g})$ in sample H3 (Flowers honey) and minimum concentration reached to $(36 \mathrm{~g} / 100 \mathrm{~g}$ ) in sample H2 (Ziziphus honey).
The present study pointed to the mean total sugar content of examined honey ranging from 60.0 to $80.3 \mathrm{~g} / 100 \mathrm{gm}$. Fructose was found in higher concentrations than glucose. These results agreed with the findings of previous studies on monofloral honey (Ouchemoukh et al., 2010; León-Ruiz et al., 2011). Sucrose was considered as an indicator of honey quality; the percentage of sucrose to total sugar in honey increased when honey was harvested before ripening. During the ripening process, in the cell, the sucrose level is reduced by the action of enzyme invertase (Bogdanov et al., 1999).

Table 3. Sugar composition $(\mathrm{g} / 100)$ for the five tested honey samples.

\begin{tabular}{ccccc}
\hline Sample & Glucose & Fructose & Sucrose & Glucose + Fructose \\
\hline Sample (H1) & 24.0 & 36.84 & 0 & 60.84 \\
Sample (H2) & 26.60 & 39.72 & 0 & 66.30 \\
Sample (H3) & 31.00 & 46.00 & 0 & 77 \\
Sample (H4) & 36.00 & 40.00 & 0 & 76 \\
Sample (H5) & 38.5 & 41.8 & 0 & 80.3 \\
\hline
\end{tabular}

\section{Antioxidant}

Many natural sources can be used to overcome on effects of oxidative stress underlying the pathogenic disease, the DPPH radical scavenging activity of honey was assayed by DPPH radical scavenging methods, the results were illustrated in (Table 4). In comparison among the honey samples, the highest antioxidant activity was shown in sample H4 (Alfalfa honey), being the best in terms of antioxidant activities among the 5 types of honey samples. This is followed by sample $\mathrm{H} 2$ (Ziziphus honey) and minimum scavenging activity was determined by sample $\mathrm{H} 5$ (Tamarisk honey). All honey samples were statistically significant compared to the ascorbic 
acid (AC), except for sample H5 (Tamarisk honey).

The results also showed that Alfalfa honey has the highest antioxidants $(95.42 \mathrm{mg} / \mathrm{ml})$ and the lowest DPPH antioxidant activity was 10.70 $\mathrm{mg} / \mathrm{ml}$ of Tamarisk honey; while Ziziphus honey determined by DPPH activity was $63 \mathrm{mg} / \mathrm{ml}$. Another study by Aziz \& Tuba (2018) reported that the DPPH radical scavenging of pine honey was $65.52 \mathrm{mg} / \mathrm{ml}$ and strawberry honey recorded $54.25 \mathrm{mg} / \mathrm{ml}$. This agrees with our study where most of the honey samples demonstrated high values of DPPH and the antioxidant potential is correlated to the mineral content in honey samples ( $\mathrm{Zn}, \mathrm{Al}$, and $\mathrm{Fe}$ ) and also the phenolic content, where natural honey is well known of its high amounts of phenolic compound, salicylic, and gallic acid. Chua et al. (2013) and Gül \& Pehlivan (2018) found a positive correlation between the antioxidant and chemical content of honey-like phenolics and vitamins, which is in agreement with the current study.

Table 4. Mean DPPH scavenging activity of the five honey samples (Mean \pm S.D.).

\begin{tabular}{ccccccc}
\hline Test & H1 & H2 & H3 & H4 & H5 & AC \\
\hline $\begin{array}{c}\text { DPPH } \\
(\mathrm{mg} / \mathrm{ml})\end{array}$ & $88.01 \pm 0.01$ & $63.21 \pm 0.01$ & $78.22 \pm 0.02$ & $95.4 \pm 0.012$ & $10.72 \pm 0.01$ & $66.33 \pm 0.001$ \\
\hline
\end{tabular}

AC: Ascorbic acid; S.D.: Standard deviation

Table 5. Antimicrobial activity of tested honey samples.

\begin{tabular}{lccccc}
\hline \multirow{2}{*}{ Samples } & \multicolumn{5}{c}{ Zone of inhibition (mm) } \\
\cline { 2 - 6 } & \multicolumn{6}{c}{ Gram-positive bacteria } & Gram-negative bacteria & Yeast \\
\cline { 2 - 6 } & $12.0 \pm 0.0$ & $8.5 \pm 0.5$ & $9.0 \pm 0.0$ & Eac & Cand \\
\hline Sample H1 & $8.5 \pm 0.5$ & $9.0 \pm 1.0$ & $8.5 \pm 0.5$ & $8.0 \pm 0.0$ & $6.0 \pm 0.0$ \\
Sample H2 & $8.0 \pm 0.0$ & $8.0 \pm 0.0$ & $8.5 \pm 0.5$ & $8.5 \pm 0.5$ & $6.0 \pm 0.0$ \\
Sample H3 & $8.5 \pm 0.5$ & $8.5 \pm 0.5$ & $9.0 \pm 0.0$ & $8.5 \pm 0.5$ & $6.0 \pm 0.0$ \\
Sample H4 & $9.5 \pm 0.5$ & $8.0 \pm 0.0$ & $8.5 \pm 0.5$ & $7.0 \pm 0.0$ & $6.0 \pm 0.0$ \\
Sample H5 & $26.5 \pm 0.5$ & $30.5 \pm 0.5$ & $11.5 \pm 0.5$ & $27.0 \pm 0.0$ & - \\
Chloramphenicol $(1.25 \mathrm{mg} / \mathrm{ml})$ & - & - & - & - & $23.5 \pm 0.5$ \\
Clotrimazole $(2.5 \mathrm{mg} / \mathrm{ml})$ & - & - & &
\end{tabular}

Table 6. Minimum inhibitory concentration (MIC) of the honey sample 1.

\begin{tabular}{cccccc}
\hline \multirow{2}{*}{ Microorganism } & \multicolumn{5}{c}{ Minimum inhibitory concentration (MIC) $\%$} \\
\cline { 2 - 5 } & $25 \%$ & $12.5 \%$ & $6.3 \%$ & $3.1 \%$ & $1.6 \%$ \\
\hline Staphylococcus aureus ATCC BAA 1026 & + & + & - & - & - \\
\hline
\end{tabular}

\section{Antimicrobial properties}

Regarding the results of the antimicrobial discdiffusion susceptibility test, unlike antibiotics, there are no standard criteria for interpreting the inhibition zones for raw natural compounds. However, Philip et al. (2009) suggested that inhibition zones larger than $10 \mathrm{~mm}$ have good antibacterial activity. As shown in Tables 5 and 6, the disc diffusion test showed that honey samples have no antifungal activity against the yeast Candida albicans. Whereas, various degrees of antibacterial activity (moderate to weak) were recorded with bacteria and this moderate to weak activity was non-significant at $p \leq 0.05$. Amongst the five honey varieties, the honey sample H1, which was Acacia variety, showed the highest antibacterial activity (significant at $p \leq 0.05$ ). It recorded a $12.0 \pm 0.0 \mathrm{~mm}$ zone of inhibition against Staphylococcus aureus. Based on the methodology, bacteria that showed susceptibility to honey samples from the $10.0 \mathrm{~mm}$ inhibition zone and above were subjected to minimum inhibitory concentration (MIC). Accordingly, only Staphylococcus aureus was tested for MIC against Acacia honey. The MIC of this bacterium was $12.5 \%$. It is believed that peroxide and other bioactive constituents are the main cause of the antibacterial activity of honey (Zainol et al., 2013) 
The current findings are in agreement with previous studies which showed that Acacia honey has remarkable antibacterial activity against Staphylococcus aureus, in particular (Hegazi et al., 2017; Mohd et al., 2020). However, the other honey samples showed various antibacterial activity (less than $10.0 \mathrm{~mm}$ zone of inhibition). Hence, it is important to mention that honey is a sensitive product and many factors could affect the antibacterial potential of honey, such as the handling processes, transportation, season of collection, and storage conditions (Abdallah, 2016).

Finally, the current study revealed that honey samples showed diverse activity in terms of mineral contents, $\mathrm{pH}$, density, sugar contents, and antioxidant and antibacterial activity. This could be related to the difference in properties of the nectar source, the climate, the environmental conditions, and geographical distribution (Alghamdi et al., 2020; Al Kiyumi et al., 2021; Pauliuc et al., 2021).

\section{CONCLUSION}

In conclusion, the honey samples have revealed a significant antioxidant potential of all tested honey samples, except for the Tamarisk honey. In addition, the samples have shown a degree of antibacterial activity, which was statistically nonsignificant, except with one bacterium (Staphylococcus aureus). The physico-chemical analysis of honey samples was also discussed and uncovered many interesting constituents, which indicates various health benefits. Accordingly, honey is a valuable food not only for its nutritious value, but also for its physical, chemical, and biological capabilities. These bioactive functions are mostly due to the biochemical compounds found in honey, which may be used alone as a functional food or as potential additives in a variety of foods.

\section{CONFLICT OF INTEREST}

The authors declare that there is no conflict of interest regarding the publication of this article.

\section{REFERENCES}

Abdallah, E. M. 2020. Antibacterial potential of fresh fruit juices against multi-drug resistant pathogens. Journal of Acute Disease 9(2): 83-88.

Abdallah, E. M. 2016. Not all honey samples contain significant levels of antibacterial activity. CibTech Journal of Biotechnology $5(4): 1-5$

Abdellah, F., Makhloufi, C., Boukraa, L. et al. 2020. Physicochemical properties and antibacterial and antioxidant activity of two varieties of honey from Algerian Steppe. Journal of Apitherapy and Nature 3(2): 59-74

Adugna, E., Hymete, A., Birhanu, G., \& Ashenef, A. 2020. Determination of some heavy metals in honey from different regions of Ethiopia. Cogent Food and Agriculture 6(1): 1764182.

Ahmed, J., Prabhu, S. T., Raghavan, G. S. V., \& Nagdi, M. 2007. Physico-chemical, rheological, calorimetric and dielectric behavior of selected Indian honey. Journal of Food Engineering 79(4): 1207-1213.

Ahmed, S., Sulaiman, S. A., Baig, A. A., Ibrahim, M., Liaqat, S., Fatima, S., \& Othman, N. H. 2018. Honey as a potential natural antioxidant medicine: An insight into its molecular mechanisms of action. Oxidative Medicine and Cellular Longevity: 1-19.

Alam, M. N., Bristi, N. J., \& Rafiquzzaman, M. 2013. Review on in vivo and in vitro methods evaluation of antioxidant activity. Saudi Pharmaceutical Journal 21(2): 143-152.

Alghamdi, B. A., Alshumrani, E. S., Saeed, M. S., et al. 2020. Analysis of sugar composition and pesticides using HPLC and GC-MS techniques in honey samples collected from Saudi Arabian markets. Saudi Journal of Biological Sciences 27(12): 3720-3726.

Al Kiyumi, E. H., Al Rashdi, B. A., Al Alawi, A. R., et al. 2021. Quantification of bioactive components and evaluation of antioxidative potential of different floral origin honey from arid regions of Oman. Biocatalysis and Agricultural Biotechnology 33: 102007.

Al-Mamary M., Al-Meeri, A., \& Al-Habori, M. 2002. Antioxidant activities and total phenolics of different types of honey. Nutrition Research 22(9): 1041-1047.

Aljohar. H. I., Maher, H. M., Albaqami, J., et al. 2018. Physical and chemical screening of honey samples available in the Saudi market: An important aspect in the authentication process and quality assessment. Saudi Pharmaceutical Journal 26(7): 932-942.

Alqarni, A. S., Owayss, A. A., Mahmoud, A. A., \& Hannan, M. A. 2014. Mineral content and physical properties of local and imported honeys in Saudi Arabia. Journal of Saudi Chemical Society 18(5): 618-625.

Bakht, J., Islam, A., Ali, H., Tayyab, M., \& Shafi, M. 2011. Antimicrobial potentials of Eclipta alba by disc diffusion method. African Journal of Biotechnology 10(39): 7658-7667.

Bloom, D. E. \& Cadarette, D. 2019. Infectious disease threats in the twenty-first century: Strengthening the global response. Frontiers in Immunology 10:549.

Bogdanov, S., Lüllmann, C., Martin, P., et al. 1999. Honey quality and international regulatory standards: Review by the international honey commission. Bee World 80(2): 61-69.

Bogdanov, S. 2009. Harmonized methods of the international honey commission. IHC World Network of Honey Science 5: 162.

Bogdanov, S., Jurendic, T., Sieber, R., \& Gallmann, P. 2008. Honey for nutrition and health: A review. Journal of the American College of Nutrition 27(6): 677-689. 
Bouhlali, E. T., Mohamed Bammou, M., Sellam, K. et al. 2019. Physicochemical properties of eleven monofloral honey samples produced in Morocco. Arab Journal of Basic and Applied Sciences 26(1): 476-487.

Brand-Williams, W., Cuvelier, M. E., \& Berset, C. 1995. Use of a free radical method to evaluate antioxidant activity. $L W T$ Food Science and Technology 28: 25-30.

Chua, L. S., Rahaman, N. L. A., Adnan, N. A., \& Eddie, T. T. 2013. Antioxidant activity of three honey samples in relation with their biochemical components. Journal of Analytical Methods in Chemistry 10: 313798.

Cianciosi, D., Forbes-Hernández, T. Y., Afrin, S., et al. 2018. Phenolic compounds in honey and their associated health benefits: A review. Molecules 23(9): 2322.

Elsharkawy, E. R. \& Shiboob, M. H. 2017. Antioxidant activity of phenolic and alkaloid fractions accumulated in Artemisia Judaica and Artemisia Herba Alba. Journal of Natural Remedies 17(4): 154-164.

Eteraf-Oskouei, T. \& Najafi, M. 2013. Traditional and modern uses of natural honey in human diseases: A review. Iranian Journal of Basic Medical Sciences 16(6): 731-742.

Gonelimali, F. D., Lin, J., Miao, W., et al. 2018. Antimicrobial properties and mechanism of action of some plant extracts against food pathogens and spoilage microorganisms. Frontiers in Microbiology 9: 1639.

Gül, A. \& Pehlivan, T. 2018, Antioxidant activities of some monofloral honey types produced across Turkey. Saudi Journal of Biological Sciences 25(6): 1056-1065.

Hegazi, A. G., Al Guthami, F. M., Al Gethami, A. F., et al. 2017. Potential antibacterial activity of some Saudi Arabia honey. Veterinary World 10(2): 233-237.

Laaroussi, H., Bouddine, T., Bakour, M., et al. 2020. Physicochemical properties, mineral content, antioxidant activities, and microbiological quality of Bupleurum spinosum Gouan honey from the middle atlas in Morocco. Journal of Food Quality 2020: 7609454.

Lam, K. S. 2007. New aspects of natural products in drug discovery. Trends in Microbiology 15(6): 279-289.

Lazaridou, A., Biliaderis, C. G., Bacandritsos, N., \& Sabatini, A. G. 2004. Composition, thermal and rheological behaviour of selected Greek honeys. Journal of Food Engineering 64(1): 921.

León-Ruiz, V., Vera, S., González-Porto, A. V., \& Andrés, M. P. S. 2011. Vitamin C and sugar levels as simple markers for discriminating Spanish honey sources. Journal of Food Science 76(3): C356-C361.

Lullah-Deh, J. A., Khan, M. E., \& Eneji, I. S. 2018. Physicochemical characteristics of honey samples from Mambilla Plateau, Nigeria. Journal of Biomaterials 2(1): 7-11.

Mohd, M. A., Edros, R., \& Hamzah, N. A. 2020. Antibacterial properties of kelulut, tualang and acacia honey against fourteen clinically-isolated strains of bacteria-infecting wound. AIP Conference Proceedings 2252: 020001.

Otaka, A., Hokura, A., \& Nakai, I. 2014. Determination of trace elements in soybean by X-ray fluorescence analysis and its application to identification of their production areas. Food Chemistry 147: 318-326.

Ouchemoukh, S., Schweitzer, P., Bey, M. B., Djoudad-Kadji, H., Louaileche, H. 2010. HPLC sugar profiles of algerian honeys. Food Chemistry 121(2): 561-568.

Pauliuc, D., Ciursă, P., Ropciuc, S., et al. 2021. Physicochemical parameters prediction and authentication of different monofloral honeys based on FTIR spectra. Journal of Food Composition and Analysis 102: 104021.

Perez-Arquillué, C., Conchello, P., Agustin Ariño, A., et al. 1994. Quality evaluation of Spanish rosemary (Rosmarinus officinalis) honey. Food Chemistry 51(2): 207-210.
Philip, K., Malek, S. N. A., Sani, W., et al. 2009. Antimicrobial activity of some medicinal plants from Malaysia. American Journal of Applied Sciences 6: 1047-1058.

Ramsay, E. I., Rao, S., Madathil, L., et al. 2019. Honey in oral health and care: a mini review. Journal of Oral Biosciences 61(1):32-36.

Ribeiro, R. O., Mársico, E. T., de Jesus, E. F., et al. 2014. Determination of trace elements in honey from different regions in Rio de Janeiro state (Brazil) by total reflection Xray fluorescence. Journal Of Food Science 79(4): T738-T742.

Rossi, M. \& Marrazzo, P. 2021. The potential of honeybee products for biomaterial applications. Biomimetics 6(1): 6 .

Sajid, M., Yamin, M., Asad, F., et al. 2020. Comparative study of physio-chemical analysis of fresh and branded honeys from Pakistan. Saudi Journal of Biological Sciences 27(1): 173-176.

Solayman, M., Islam, A., Paul, S., et al. 2016. Physicochemical properties, minerals, trace elements, and heavy metals in honey of different origins: a comprehensive review. Comprehensive Reviews in Food Science and Food Safety 15(1): 219 233.

Svečnjak, L., Jović, O., Prđun, S., et al. 2019.Influence of beeswax adulteration with paraffin on the composition and quality of honey determined by physico-chemical analyses, $1 \mathrm{H}$ NMR, FTIR-ATR and HS-SPME/GC-MS. Food Chemistry 291: 187-198.

Utzeri, V. J., Ribani, A., Schiavo, G., et al. 2018. Application of next generation semiconductor based sequencing to detect the botanical composition of monofloral, polyfloral and honeydew honey. Food Control 86: 342-349.

Zainol, M. I., Yusoff, K. M., \& Yusof, M. Y. M. 2013. Antibacterial activity of selected Malaysian honey. BMC Complementary and Alternative Medicine 13:1 29. 